\title{
Saberes da docência de professores da educação profissional
}

\author{
GERALDO SILVESTRE SILVA JÚNIOR \\ Centro Federal de Educação Tecnológica de \\ Minas Gerais, Belo Horizonte, MG, Brasil \\ JOSÉ ÂNGELO GARIGLIO \\ Universidade Federal de Minas Gerais, \\ Belo Horizonte, MG, Brasil
}

\section{RESUMO}

Este artigo apresenta resultados de uma pesquisa de mestrado que teve como objeto o estudo dos saberes docentes de professores da educação profissional (EP) que lecionam disciplinas das áreas tecnológicas. $\mathrm{O}$ estudo, de cunho qualitativo, foi realizado com dois professores experientes, vinculados a duas instituições de EP diferentes - uma pública e outra privada - e valeu-se dos aportes teóricos produzidos em torno das pesquisas sobre a epistemologia da prática docente. Aponta-se o fato de que a aprendizagem da docência nessa modalidade de ensino é marcada por processos de formação muito particulares, em que determinados tipos de saber e experiência de formação (saberes da experiência laboral) têm mais reconhecimento que conhecimentos advindos da experiência docente ou de conhecimentos do campo pedagógico.

\section{PALAVRAS-CHAVE}

saberes docentes; epistemologia da prática profissional; formação de professores; educação profissional. 


\title{
THE TEACHING KNOWLEDGE OF EDUCATIONAL PROFESSIONALS
}

\begin{abstract}
This paper deals with the results of a master's degree research that studied teachers' knowledge of professional education (PE) within technological disciplines. The study was a qualitative matrix carried out by two experienced teachers, connected to two different institutions of $\mathrm{PE}$ - one public and one private. The research was based on theories that resulted from previous research on the epistemology of practicing teachers. The study points to the fact that the teaching of learning in this modality of education is marked by very particular processes of formation where some types of knowledge and experiences (knowledge of work experience) have more recognition than the knowledge acquired by the teaching experience or the knowledge in the pedagogical field.
\end{abstract}

\section{KEYWORDS}

teacher knowledge; epistemology of professional practice; training of teachers; professional education.

\section{SABERES DE LA DOCENCIA DE PROFESORES DE EDUCACIÓN PROFESIONAL}

\section{RESUMEN}

Este artículo presenta resultados de una investigación de maestría que tuvo como objeto el estudio de los saberes docentes de profesores de educación profesional (EP) que aleccionan cursos en las áreas de tecnología. El estudio, de carácter cualitativo, se realizó con dos profesores experimentados, vinculados a dos diferentes instituciones de educación profesional -una pública y otra privada - y consisderó los aportes teóricos en torno a la investigación sobre la epistemología de la práctica docente. Se señala el hecho de que el aprendizaje de la docencia en esta modalidad de educación está marcado por procesos de formación muy particulares, en que ciertos tipos de saber y experiencia de capacitación (conocimiento de la experiencia laboral) tienen más reconocimiento que el conocimiento oriundo de la experiencia como docente o conocimiento del campo pedagógico.

\section{PALABRAS CLAVE}

saberes docentes; epistemología de la práctica profesional; formación de profesores; educación profesional. 


\section{INTRODUÇÃO}

O tema referente aos processos de constituição dos saberes da base profissional dos professores é alvo crescente de estudos no âmbito das ciências da educação. Esses estudos têm como uma de suas preocupações a investigação das práticas de ensino dos docentes em seus diferentes e singulares locais de trabalho, identificando nessas práticas a particularidade do conhecimento e da habilidade profissional que demarcaria a especificidade do ofício docente.

Essas pesquisas, em linhas gerais, nutrem-se de questões como: $\mathrm{O}$ que sabem os professores? Quais os saberes que estão na base da profissão docente? Quais os saberes necessários para ensinar? O que esses saberes têm de original? Há diferença entre eles e os conhecimentos provenientes da formação inicial, das ciências da educação, dos conhecimentos curriculares? Caso haja, em que ponto eles são diferentes? Como esses saberes são construídos? Qual a relação entre a edificação desses saberes com a experiência profissional? Trata-se de habitus, rotinas, posturas, intuição, dom, bom senso e/ou conhecimentos de tipo sui generis e competências? Qual a relação entre os saberes profissionais e os saberes acadêmicos e disciplinares?

Essas são questões que orientaram a nossa investigação e constituem o pano de fundo no qual tem origem o nosso objeto de estudo. ${ }^{1}$ Ele se situa, portanto, no universo das pesquisas contemporâneas sobre o ensino, mais particularmente no domínio dos estudos que se interessam pelos saberes, pela formação e pelo trabalho docente.

Tendo como referência o foco investigativo desses estudos, a pesquisa por nós realizada buscou investigar os processos de construção dos saberes da base profissional de professores da educação profissional (EP), mediante as ações pedagógicas laboradas por esses docentes em meio a práticas de ensino demarcadas pelo trabalho no interior de escolas vinculadas a essa modalidade de ensino.

A pesquisa buscou encontrar resposta para as seguintes questões: Se o ofício docente é feito de saberes, quais seriam os saberes profissionais dos professores da EP? Qual a relação desses com as singularidades de uma prática docente numa escola responsável pela profissionalização de jovens e adultos? De que maneira esses saberes contribuem para fundamentar o processo de profissionalização docente desses profissionais do ensino?

Enfim, nosso objeto de estudo visou compreender os modelos ou tipos de ação desenvolvidos pelos professores de $\mathrm{EP}$ em virtude de uma inserção profissional na escola que, a priori, parecia-nos detentora de um conjunto de particularidades. Estamos entendendo aqui como modelos de ação as representações elaboradas e veiculadas pelos professores da EP a respeito da natureza de sua prática; representações que servem para defini-la, estruturá-la e orientá-la em situações de ação (Tardif, 2007).

1 Este artigo é uma síntese da dissertação defendida pelo autor Geraldo Silvestre Silva Júnior, em 2010, no mestrado em educação tecnológica do Centro Federal de Educação Tecnológica de Minas Gerais (CEFET-MG). 


\section{A ORIGEM DO PROBLEMA}

O tema da formação de professores para a EP no Brasil nos remete à história dessa modalidade de ensino, na sua relação com o processo de constituição do sistema educacional no país. É corrente na literatura a constatação de que o ensino técnico foi criado com o intuito de atender aos interesses e às necessidades produtivas do mundo empresarial. A desarticulação entre a educação regular e a rede de formação profissional paralela, gerenciada pelas próprias indústrias - Sistema $\mathrm{S}$-, permitiu a essas instituições de formação profissional desenvolver uma mentalidade nitidamente empresarial e incorporar, em sua estrutura e organização, procedimentos eminentemente utilitários (Peterossi, 1994).

Em razão dessa percepção, acreditava-se que a aprendizagem dos ofícios manuais poderia se dar pelo simples contato entre um artesão/operário experiente e um aprendiz. Essa ideia - muito presente nas práticas culturais de aprendizagem dos ofícios profissionais - foi escolarizada com a criação das escolas de aprendizes e artífices pelo presidente Nilo Peçanha, em $1909 .{ }^{2}$ Essas escolas contribuíram para disseminar a compreensão de que aquele que sabe fazer é capaz de ensinar, sobretudo quando essa formação se destina aos setores excluídos da sociedade: órfãos, abandonados e "desvalidos da sorte".

Essa perspectiva reducionista permitiu que se enraizasse uma mentalidade que perdura até os dias de hoje: a noção de que, para ser professor de disciplinas ou áreas tecnológicas, mais vale o conhecimento dos conteúdos que se vai lecionar que propriamente a formação pedagógica (Macieira, 2009). Enquanto a EP ganhava impulso, expandia-se e estruturava-se no país, a formação dos seus professores nunca alcançou o reconhecimento necessário, o que se manifesta na negligência do poder e dos gestores públicos com relação à matéria.

Em um primeiro nível de análise, essa visão nos parece ser alimentada por uma história de política de não formação (Peterossi, 1994) destinada aos professores que atuam no âmbito da EP. Para essa autora, a formação pedagógica desse professor vem sendo tratada, no país, como algo especial, emergencial, sem integralidade própria e viabilizando propostas de formação aligeirada e superficial, que carece de marco regulatório (Oliveira, 2005).

Acompanhando as características gerais das políticas públicas no campo da formação de professores para o ensino técnico, pode-se afirmar também, grosso modo, que estudos sobre a temática, bem como a organização dos educadores em torno de debates a respeito, vêm se desenvolvendo de forma descontínua, muito em razão de momentos especiais em que essa formação é posta em questão. Até dentro da Associação Nacional pela Formação dos Profissionais da Educação (ANFOPE) não há referências significativas e frequentes a esses professores e à sua formação na produção sobre formação de professores e no debate sobre políticas e propostas de formação defendidas por essa entidade em suas relações com as políticas e propostas oficiais e vigentes (idem).

2 Decreto n. 7.566 , de 23 de setembro de 1909. 
Assim, não tem sido construída uma cultura de produção acadêmico-científica na área. Esse desinteresse pela temática pode ser percebido também dentro de importantes fóruns que discutem a educação nacional. Nesse sentido, o campo científico-tecnológico da formação do professor do ensino técnico vem se mostrando frágil como um campo próprio e estável de conhecimento. Segundo Macieira (2009, p. 23),

[...] a produção da Associação Nacional de Pós-Graduação e Pesquisa em Educação (ANPEd), entre 1996 e 2001, e dos Encontros Nacionais de Didática e Prática de Ensino (ENDIPEs), de 1996 a 1998, não contempla a formação de professores para o ensino técnico. [...] nos ENDIPEs realizados em 2004 e 2006, encontram-se apenas 5 trabalhos relacionados objetivamente ao referido assunto. E no I Simpósio de Grupos de Pesquisa sobre Formação de Professores no Brasil, promovido pela ANPAd em julho de 2006, dos 71 grupos participantes, apenas um desenvolve pesquisas ligadas ao ensino técnico (justamente o FORPROFET).

Estudos sobre o estado da arte nas pesquisas sobre a formação de professores no Brasil, na última década, confirmam esse silenciamento na produção intelectual. $\mathrm{Na}$ década de 1990, André et al. (1999, grifo nosso) elaboraram um estudo sobre o "Estado da arte da formação de professores no Brasil" analisando a produção de conhecimento em 284 teses e dissertações nos programas de pós-graduação em educação, no período de 1990 a 1996; em 115 artigos de dez periódicos, entre 1990 e 1997; e em 70 trabalhos do Grupo de Trabalho "Formação de Professores", da Associação Nacional de Pós-Graduação e Pesquisa em Educação (ANPEd), entre 1992 e 1998.

A pesquisa identificou que houve preocupação significativa com a formação do professor para atuar no ensino fundamental, nas séries iniciais. Mas, em contrapartida, em relação à produção de conhecimento na área educacional, André et al. registraram a negligência e "[...] o silêncio quase total em relação à formação do professor para o Ensino Superior, para a Educação de Jovens e Adultos, para o Ensino Técnico e Rural, para atuar nos Movimentos Sociais e com crianças em situação de risco" (idem, p. 309, grifo nosso).

Além desse estudo, destacamos os trabalhos de André (2000) e de Brzezinski (2006). Em todos eles, manifestou-se contundente carência de pesquisas que tratassem da formação de professores da EP. O levantamento preliminar da produção acadêmica na área da educação, presente no texto do projeto de pesquisa FORPROFET, ${ }^{3}$ feito pelo Grupo de Pesquisa em Teoria e Metodologia do Ensino Tecnológico (PETMET), vinculado ao mestrado em educação tecnológica do CEFET-MG, também evidencia que

3 Projeto de pesquisa elaborado para aprovação da pesquisa "Formação de professores do ensino técnico - FORPROFET" nas agências financiadoras Conselho Nacional de Desenvolvimento Científico e Tecnológico (CNPq) e na FAPEMIG. O projeto foi aprovado e a pesquisa realizada no período de 2006-2008. 
[...] no âmbito da produção intelectual de dissertações, teses e livros, encontraram-se apenas duas dissertações (Alves, 2001; Ferreira, 2001) e um livro sobre a matéria (Peterossi, 1994), no período de 1994 a 2003. Particularmente sobre a formação continuada do professor de ensino técnico, o estudo de Araújo (2004) indica a existência, no período de 1996 a 2004, de apenas um trabalho num conjunto de 395 outros sobre formação de professores identificados em várias fontes. ${ }^{4}$

$\mathrm{Na}$ avaliação de Oliveira (2005, p. 33), esse cenário em nada contribuiu para o fortalecimento da área; muito pelo contrário, essa situação dificultou e fragilizou o campo de estudo, "[...] que informa uma produção científica densa, consistente e socialmente reconhecida, e que é informado por ela [...]", pouco acrescentando à profissionalização do ensino e à formação profissional desse professor.

Esse desinteresse da produção intelectual pelo tema da formação de professores da EP vem contribuindo para reforçar a tese de que esses profissionais não pertencem à área da educação e que a eles cabe, apenas, o domínio dos conhecimentos $\mathrm{da}(\mathrm{s})$ área(s) na(s) qual(is) pretendem ensinar e a experiência no chão de fábrica.

A esse respeito, é importante lembrar que as pesquisas sobre a formação de professores surgem ligadas à questão da profissionalização do ensino e do magistério, no esforço de pesquisadores em definir a natureza dos conhecimentos profissionais que serviriam de base ao exercício da docência. Essa definição ajudaria os governos a projetar padrões curriculares nacionais para a formação de professores, assim como metas a serem alcançadas pelos centros de formação inicial e continuada. Pode-se concluir, portanto, que o desinteresse do campo da educação em produzir estudos e ações propositivas ao desenvolvimento da formação inicial e continuada de professores da EP tem contribuído ou reforçado a visão de que esses profissionais não pertencem à área da educação e que podem ser substituídos por instrutores ou monitores. Melhor dizendo, esse silenciamento das pesquisas contribui para o arrefecimento da luta pela conquista da profissionalização do magistério na EP.

No intuito de romper essa tendência, o presente trabalho intenciona contribuir para o avanço desse debate, fazendo uma discussão inicial acerca dos saberes mobilizados pelos docentes da EP. Pretende também analisar os saberes acionados e demandados pelos docentes nas suas atividades educativas e as concepções de formação profissional subjacentes a tais saberes. Assim, busca-se analisar que tipos de saber são demandados por esses professores para o exercício da docência, as formas de acesso a esses saberes e as concepções de formação que tais demandas indicam.

4 Trata-se das seguintes fontes: banco de dados das bibliotecas do CEFET-MG, da Pontifícia Universidade Católica de Minas Gerais (PUC-MG), da Universidade Estadual de Campinas (UNICAMP), da Universidade Federal de Minas Gerais (UFMG) e da Universidade de São Paulo (USP); banco de dissertações e teses da Coordenação de Aperfeiçoamento de Pessoal de Nível Superior (CAPES) e do Instituto Brasileiro de Informação em Ciência e Tecnologia (IBICT); anais do $8^{\circ}$ ao $11^{\circ}$ Encontro Nacional de Didática e Prática de Ensino (ENDIPE); anais da 19a à 26 ${ }^{\mathrm{a}}$ Reunião Anual da ANPEd; periódicos da área (Caderno CEDES, Cadernos de Pesquisa, Educação e Pesquisa, Educação em Revista, Educação Eo Sociedade, Revista Brasileira de Educação e Educação Ẽ Tecnologia). 


\section{A DOCÊNCIA NA EP: UM OFÍCIO SEM SABERES?}

Os estudos sobre o saber docente ganham força no início dos anos 1980 e certo prestígio na década de 1990, principalmente nos Estados Unidos. Essa produção teórica cresce em importância, entre outros motivos, pela constatação da dificuldade da escola em lidar com as novas exigências socioculturais advindas da concorrência internacional, decorrente da globalização dos mercados e da crise do papel social da escola, bem como da complexidade dos sistemas nacionais de ensino para lidar com uma escola de massa. ${ }^{5}$

A crise da escola é atribuída, entre outras causas, à fragilidade da profissão docente, especialmente a pouca importância dada à formação dos professores e ao embaraço desses em trabalhar com as novas e complexas exigências sociais, pedagógicas e culturais. ${ }^{6}$ Assim, o que se apresenta como um remédio para os males evidenciados pelos fatores precedentes é o discurso que defende a necessidade de profissionalizar o magistério (Tardif; Lessard; Lahaye, 1991; Gauthier; Martineau; Desbien, 1998). ${ }^{7}$

As pesquisas sobre os saberes docentes surgem como se fossem ligadas à questão da profissionalização do ensino e aos esforços feitos pelos pesquisadores em definir a natureza dos conhecimentos profissionais que serviriam de base para o magistério. Essa definição ajudaria os governos a projetarem padrões curriculares nacionais para a formação de professores, assim como metas a serem alcançadas pelos centros de formação inicial e continuada.

Gauthier, Martineau e Desbiens (1998) buscam aprofundar essa discussão apontando que o saber necessário para ensinar não pode ser reduzido ao conhecimento do conteúdo da disciplina. Quem ensina sabe muito bem que, para fazê-lo, é preciso muito mais que simplesmente conhecer a matéria, mesmo reconhecendo que esse conhecimento seja fundamental. Nesse sentido, acreditou-se por muito tempo que as habilidades necessárias à docência podiam ser resumidas ao talento natural dos professores, ou seja, ao seu bom senso, à sua intuição, à sua experiência ou mesmo à sua cultura. Essas ideias preconcebidas prejudicavam o processo de profissionalização do ensino, impedindo o desabrochar de um saber desse ofício

5 A dificuldade da escola em lidar com o "déficit" cultural dos alunos das classes populares, que até então não tinham conquistado o direito de frequentar os bancos escolares, acabou por provocar o aumento dos índices de evasão e repetência escolar. Tal fato leva a um questionamento da atuação da escola, assim como dos professores, a ponto de colocar em xeque sua legitimidade social.

6 Martin (1993), ao fazer uma análise dos estudos sobre os saberes docentes produzidos no universo anglo-saxão, revela que esses estudos repousam, principalmente, sobre a dificuldade dos sistemas escolares de produzir estudantes convenientemente formados.

7 Alguns estudos de grande fôlego que visavam fazer profundos diagnósticos sobre a situação do ensino, como o Relatório Coleman (1966), ajudaram a propagar a ideia de que o ensino e o trabalho do professor não eram variáveis importantes na explicação do desempenho dos alunos, comparativamente à influência preponderante do meio social. Esses estudos contribuíram para alimentar a ideia de que não era necessário melhorar o desempenho dos professores (Gauthier; Martineau e Desbiens, 1998; Woods, 1995). 
sobre si mesmo.É o que os autores denominam de um ofício sem saberes. Isso porque tais saberes permaneceram por muito tempo confinados à sala de aula, resistindo à própria conceitualização, sendo mal expressados pelos profissionais.

Simultaneamente, o ideal de criar uma pedagogia científica, de redigir um código do saber-ensinar, contribui para desprofissionalizar a atividade docente, visto que esse ideal de cientificidade demonstrou dificuldade de passar no teste na prática. Isso se deve ao fato de que esses códigos, construídos dentro dos moldes da racionalidade técnica, tinham a limitação de não levar suficientemente em conta a complexidade e as inúmeras dimensões concretas da situação pedagógica.

Assim como as ideias preconcebidas de um ofício sem saberes bloqueavam a constituição de saber pedagógico, do mesmo modo essa versão universitária, científica e reducionista dos saberes negava a complexidade do contexto de ensino, impedindo o surgimento de um saber profissional. É como se, fugindo de um mal, se caísse em outro, ou seja, passou-se de um ofício sem saberes a saberes sem ofício; saberes que podem ser pertinentes em si mesmos, mas que pouco são reexaminados à luz do contexto real e complexo da sala de aula (idem, ibidem).

O reconhecimento de que, nos fenômenos práticos, entre eles o ato pedagógico existe uma reflexão na ação, componente inteligente que orienta toda a atividade humana e se manifesta no saber-fazer, ajudou a colocar o trabalho docente como tempo e espaço de intervenção profissional, em que se laboram práticas pedagógicas que comportam reflexões e saberes próprios porque trazem as marcas de um ofício singular. Para esses autores, se o ofício docente é feito de saberes, o desafio da profissionalização deve motivar o docente a investigar os saberes próprios do ensino, sendo necessária, para isso, a produção de estudos que consigam revelar o contexto complexo nos quais os professores encontram-se mergulhados.

Seria, então, o ofício docente na EP um ofício de saberes? Nossa pesquisa buscou identificar os conteúdos dos saberes profissionais dos professores da EP, valendo-se dos discursos que estes seguem acerca do cotidiano de sua prática docente.

\section{PROCEDIMENTOS METODOLÓGICOS}

\section{LÓCUS DE ESTUDO E SUJEITOS DA PESQUISA}

Nossa pesquisa foi realizada com professores vinculados a duas escolas profissionalizantes no município de Belo Horizonte, ambas com larga tradição e credibilidade na EP. Uma das instituições selecionadas para a pesquisa é uma escola pública pertencente à rede federal de educação tecnológica. A segunda escola pertence à rede de formação profissional do Sistema $\mathrm{S}$.

Para selecionar os professores, ou seja, os sujeitos da pesquisa, em conformidade com o objetivo de investigação, estabelecemos os seguintes critérios para definição do perfil desses sujeitos: serem professores de disciplinas das áreas tecnológicas, terem formação superior, não terem formação em curso de licenciatura plena e/ou em curso 
de formação pedagógica, ${ }^{8}$ terem mais de cinco anos de experiência na docência do ensino técnico em disciplinas técnicas e pertencer ao quadro efetivo da instituição.

A opção de trabalharmos com professores que detêm formação de nível superior e que não possuem formação pedagógica é explicada pela constatação de que, em tal contexto de atuação docente, a maioria dos professores está engajada nessa trajetória de formação acadêmica. Segundo dados obtidos no Censo da Educação Profissional de 1999 (Brasil, 1999), realizado pelo Instituto Nacional de Pesquisas Espaciais (INPE), 82,3\% dos professores que atuam nessa modalidade de ensino possuem graduação. ${ }^{9}$ No que diz respeito ao número de professores com licenciatura, não existem dados empíricos disponíveis que nos permitam apontar parâmetros de ordem quantitativa. Todavia, em virtude do quadro de desregulamentação da profissão do docente na EP e de inexistência de políticas consistentes e contínuas de formação docente para os profissionais dessa área, pode-se assegurar que uma porcentagem muito pequena de docentes que atuam nessa modalidade de ensino possui cursos de licenciatura.

Em relação à opção de trabalharmos com docentes que apresentam o tempo mínimo de cinco anos de docência na EP, a intenção foi compor um quadro de sujeitos que abarcasse elementos experienciais que se transformaram em uma "[...] maneira pessoal de ensinar, em macetes da profissão, em habitus, em traços da personalidade profissional [...]" (Tardif, 2007, p. 51). Essa condição de "saber experienciado" se aproxima das características que demarcariam a segunda fase de evolução da carreira ${ }^{10}$ docente, que é chamada de estabilização e de consolidação. Importante ressaltar que, ao nos referirmos à condição de saber experienciado, estamos considerando que

[...] essa experiência não deve ser confundida com a ideia de experimentação, considerada numa perspectiva positivista e cumulativa do conhecimento, nem com a ideia de experiencial, referente, numa visão humanista, ao foro interior psicológico e aos valores pessoais. O saber é experienciado por ser experimentado no trabalho, ao mesmo tempo em que modela a identidade daquele que trabalha. (idem, p. 110)

Nessa fase, o professor tem o reconhecimento da sua capacidade pelos seus pares e, além disso, adquire confiança maior em si mesmo e mais "[...] domínio dos diversos aspectos do trabalho, principalmente os pedagógicos (gestão da classe, planejamento do ensino, apropriação pessoal dos programas etc.) [...]”(idem, p. 84). Isso não acontece antes desse momento, no início da carreira (a chamada "fase de

8 Os cursos de formação pedagógica têm o caráter de licenciatura especial para atender ao requisito legal da resolução n. 2/1997, que é habilitar professores de disciplinas específicas para a docência por meio de programas pedagógicos especiais.

9 Disponível em: <http://www.inep.gov.br/basica/levantamentos/outroslevantamentos/ profissional/>. Acesso em: 8 ago. 2011.

10 Entendemos "carreira" como "[...] a trajetória dos indivíduos através da realidade social e organizacional das ocupações, pouco importa seu grau de estabilidade e sua identidade" (Tardif, 2007, p. 79). 
exploração"), quando eles entram num processo de aprendizagem rápida que tem valor de confirmação, ou seja, estão envolvidos na e com a prática: “[...] tendo que aprender fazendo, os professores devem provar a si próprios e aos outros que são capazes de ensinar [...]" (idem, p. 51). É uma fase marcada por tentativas e erros.

Quanto ao terceiro ponto - pertencimento do professor ao quadro de funcionários efetivos da instituição -, procuramos nos certificar de que a condição funcional dos nossos sujeitos de pesquisa favorecia o exercício da profissão de professor de forma regular e contínua. Esse dado é de suma importância, em primeiro lugar porque está ligado à questão da "estabilidade" è questão da formação e profissionalização docente e, em segundo, porque os professores irregulares, temporários, podem encontrar-se em situação precária (idem, p. 89),

[...] vivem outra coisa e sua experiência relativa à aprendizagem da profissão é mais complexa e mais difícil, pois comporta sempre uma certa distância em relação à identidade e à situação profissional bem definida dos professores regulares. É difícil pensar na consolidação de competências pedagógicas enquanto os professores com serviços prestados não tiverem adquirido um mínimo de estabilidade.

Na montagem do perfil dos professores que participariam da pesquisa, objetivamos trabalhar com sujeitos representativos do campo da EP, com rica cultura profissional no campo da docência e que apresentassem todas as condições de serem parceiros no processo de compreensão dos saberes que estão na base da profissão docente nessa área de formação.

\section{TÉCNICA DE COLETA DE DADOS}

A entrevista apresentou-se como a ferramenta metodológica central para nossa investigação. Dado o objetivo de pesquisa que centrou a análise sobre as características dos saberes docentes de professores da EP, segundo as próprias descrições feitas por eles, a entrevista apresentou-se como fundamental para acessar a complexidade e as particularidades da racionalidade prática dos professores pesquisados.

A respeito dessa questão, cabe ressaltar a discussão sobre a entrevista compreensiva desenvolvida por Kaufmann (1996). Para ele, a entrevista não se limita apenas a colher informações sobre uma realidade. Ao se engajar e se entregar no momento da entrevista, o entrevistado desenvolve intenso e profundo trabalho sobre si mesmo para construir a própria identidade, assim como sobre a realidade social na qual está inserido.

Por entendermos que numa entrevista se produz um ambiente no qual o pesquisador tem acesso a importantes informações da vida privada do pesquisado, decidimos fazer as entrevistas com todos os sujeitos da pesquisa, ao final de nossa trajetória investigativa. A escolha do momento das entrevistas teve como objetivo esperar até que o sentimento de confiança mútua já estivesse mais aprofundado, operando a entrevista quando o sentimento de estranheza ou constrangimento, diante de nossa presença na escola, já havia diminuído significativamente. 
Ainda acerca da opção metodológica, levamos em consideração o instigante debate estabelecido por Tardif e Lessard (2008) sobre a conceituação do que defendem como o "saber". Para os autores, saber qualquer coisa ou fazer qualquer coisa de forma racional é ser capaz de responder às questões "por que você fez isso?", "por que você diz isso?", oferecendo razões, motivos e justificativas susceptíveis de servirem de validação ao discurso ou à ação.

Nesse espírito, não basta fazer bem uma coisa, é preciso também que o ator saiba por que faz algo de certa maneira. Os autores levantam essa questão com o objetivo de evitar que as pesquisas sobre os saberes docentes continuem a ser vítimas do que eles chamam de "excesso etnográfico", ou seja, em que tudo é tomado como saber: ideologias, crenças, sentimentos, emoções, intuição, habitus e rotinas. E perguntam: "Se tudo é saber, para que então estudar o saber?". Para eles, os saberes docentes seriam definidos como todos os atos e discursos nos quais os práticos são capazes de fornecer razões visando a motivá-los.

Assim, o uso da entrevista mais ao final do percurso investigativo também teve como objetivo recolher o maior número de informações possível sobre o trabalho dos professores, a fim de que eles pudessem, de maneira clara, explicar os motivos e intenções orientadoras de suas práticas docentes.

Com a utilização da entrevista, foi factível acessar informações importantes que nos ajudaram a entender melhor determinadas características do conhecimento profissional dos professores: sua conduta, seu comportamento intencional dotado de significados, sua justificação, narrativas explicativas, sequências de informação, reflexão a posteriori, entre outros elementos.

Ao entendermos que os saberes docentes são eminentemente interativos, construídos na relação com os demais atores da escola e mediados pelo conjunto de regras e normas da vida institucional, fez-se necessário realizar uma descrição do trabalho desses docentes na sala de aula. Partimos da compreensão de que a observação direta se apresenta como instrumento fundamental de análise dos significados que os professores atribuem à realidade que os cerca e às próprias ações.

Tardif, Lessard e Lahaye (1991) ratificam a importância da observação nos estudos sobre os saberes dos professores, quando nos lembram de que a relação entre o conhecimento sobre o trabalho e o trabalho não apresenta transparência perfeita e controle completo: o trabalho constitui sempre um momento de alteridade ante a consciência do professor. O professor possui saberes, regras, rotinas e recursos incorporados ao seu trabalho, sem que ele tenha conhecimento explícito sobre essa posse. Diante do exposto, esses autores defendem que uma teoria consistente sobre os saberes dos professores não pode repousar exclusivamente sobre o discurso deles. Faz-se necessário observá-los no momento do ato pedagógico. ${ }^{11}$

Concordando com a procedência dessa orientação, conduzimos três meses de observação do trabalho dos professores. Todas as observações foram feitas por

11 Ao desenvolver o conceito sobre professor reflexivo, Schon (1992) reforça o alerta feito por Tardif e colaboradores, afirmando que, apesar de o recurso da reflexão ser parte inerente ao desempenho do bom professor, este não percebe isso muito claramente. 
meio do recurso de anotações em um diário de campo, que era dividido em três partes: descrição dos momentos observados; conversas com os professores após as aulas; observações e reflexões do pesquisador. Na primeira parte, anotavam-se os acontecimentos ocorridos nas aulas. Já a segunda era destinada aos relatos dos professores sobre questões que fazíamos imediatamente após a aula. Essas questões diziam respeito a determinadas intervenções dos professores durante a aula, as quais não ficavam muito claras e que achávamos importante que fossem esclarecidas. A terceira parte do diário de campo dizia respeito às (nossas) reflexões, identificação de fatos e atitudes recorrentes; indagações e perguntas norteadoras referentes aos fatos e acontecimentos por nós relatados. Tais reflexões eram registradas no mesmo dia em que as descrições das aulas eram feitas.

Com esses dois procedimentos de coleta de dados, buscamos comparar discursos distintos, confrontar posições de diferentes sujeitos sobre o mesmo tema e verificar contradições entre práticas e discursos.

\section{ANÁLISE DOS RESULTADOS DA PESQUISA}

Ao tomarmos consciência de que a carreira docente é um processo de identificação e incorporação dos indivíduos às práticas e rotinas institucionalizadas dos grupos de trabalho, compreendemos, por consequência, que os saberes dos professores edificados nesse percurso de socialização profissional trazem as marcas das experiências dessa trajetória, sendo, portanto, situados, porque construídos em função das situações particulares e singulares de trabalho. É nessa relação específica de trabalho que esses saberes ganham sentido e validade. São, assim, saberes profissionais encravados, embutidos, encerrados em uma situação de trabalho à qual devem atender. Nessa perspectiva, procuramos analisar os saberes docentes de professores da educação profissional técnica de nível médio, conforme a concepção dos próprios professores sobre os seus saberes.

Entre os aspectos mais ressaltados pelos docentes quando questionados sobre o tipo de formação que o professor da EP deveria ter, apareceu como recorrente a leitura de que a experiência no chão de fábrica seria tão importante quanto a titulação na graduação e na pós-graduação. Essa visão é descrita respectivamente pelos professores Célio (Escola A) e Saulo (Escola B $)^{12}$ nos depoimentos abaixo:

Eu achava que, depois de graduado e agora, por exemplo, na Escola A, para entrar para concurso exige no mínimo mestrado, mas eu acho, em cima disso, deveria contar também tempo de experiência na indústria. Com certeza, deveria ser. Isso é coisa que nós discutimos aqui, entre professores, o processo de seleção deveria contar tempo de experiência lá fora, trabalhando em chão de fábrica. É o que tá acontecendo hoje, com esses novos, faz graduação, entra direto no mestrado, do mestrado ao doutorado, e quem faz mestrado e doutorado não tem tempo de trabalhar na fábrica não. Tem tempo não, é dedicar só mesmo.

$12 \mathrm{O}$ nome dos professores citados na pesquisa é fictício. 
Então, que experiência, vivência que ele vai ter de chão de fábrica, nenhuma. (Professor Célio)

Então, é 50\% prática mesmo, o chão de fábrica, vivência de manusear equipamento, pegar, e os fenômenos, sentir os fenômenos, conhecer os fenômenos, então eu acho que a principal diferença é essa. (Professor Saulo)

A fala dos professores aponta para o fato de que a experiência do chão de fábrica proporcionaria ao professor da EP conhecimentos e habilidades importantes que a formação acadêmica não poderia suprir. Eles parecem afirmar que a experiência oriunda da pedagogia da fábrica (Kuenzer, 1999) ${ }^{13}$ forneceria um conjunto de saberes que seriam necessários ao exercício da docência na EP e que a formação acadêmica e os conhecimentos científicos não seriam capazes de fazê-lo.

No intuito do aprofundamento da análise desse dado constatado pela pesquisa, buscamos estabelecer um diálogo com as reflexões construídas por Dejours (1993) sobre o desenvolvimento da inteligência prática dos trabalhadores. Para o autor, a inteligência prática está enraizada no corpo. Assim é que os primeiros sinais de um evento (anormalidade) passam pelos sentidos, que acusam algum desconforto: um ruído, uma vibração, um cheiro, desde que exista uma experiência anterior comum à situação de trabalho. É essa dimensão corpórea que distingue a inteligência prática do raciocínio lógico. É o corpo, pela percepção, que orientará a ação conferindo inteligência a uma direção, de modo a proceder a um rápido diagnóstico sucedido de intervenção, cuja temporalidade é inversa à de um raciocínio científico, que virá depois, para verificar, operacionalizar e disseminar a prática que lhe foi sugerida pela intuição. A inteligência prática, assim concebida, implica desconsideração e, em alguns casos, desobediência ao trabalho prescrito, no todo ou em parte, bem como aos conhecimentos técnicos e científicos.

Por isso Dejours a chama de inteligência ardilosa, uma vez que, nesse caso, o pensamento zomba do rigor. É o reino da malícia, da esperteza, da astúcia do pensamento rápido que são necessários para o estabelecimento de determinadas relações de produção. Para o autor, mesmo afirmando que a inteligência prática seja fundamentalmente corpórea, não implica ausência do pensamento, embora conduza a modelizações práticas e representações metafóricas do conhecimento técnico que não correspondem a cálculos ou aplicações rigorosas de procedimentos e instruções. Finalmente, observa o autor, a inteligência ardilosa é criativa, fazendo surgirem outras respostas, materiais, ferramentas e processos.

Conforme os relatos do professores, o saber-fazer pedagógico na EP requer muito mais que o domínio dos conhecimentos eruditos, científicos e codificados, provenientes dos currículos e das disciplinas universitárias. $\mathrm{O}$ reconhecimento da competência para o ensino na EP passaria necessariamente pela incorporação de

13 Para Kuenzer (1999), a pedagogia da fábrica possibilitaria aos trabalhadores, além da aprendizagem dos conhecimentos específicos para produzir os bens materiais para sua sobrevivência, aprender os valores, os comportamentos e o funcionamento da pedagogia do trabalho capitalista. 
um repertório prático que seria adquirido pela experiência como trabalhador no chão de fábrica. A inteligência ardilosa parece ser, portanto, um conteúdo fundante ao repertório dos conhecimentos da base profissional dos docentes dessa modalidade de ensino. Primeiro, como uma fonte de conhecimentos didáticos (saber-fazer) que auxiliariam no ato de ensinar os elementos da cultura tecnológica. Segundo, como um conteúdo de ensino traduzido em um reservatório de experiências que seriam transmissíveis aos futuros técnicos.

Essas experiências de formação aparecem como um elemento muito importante do processo de constituição do que Shulman (1986) chama de "conhecimento do conteúdo pedagógico", ou seja, aquele amálgama especial de conteúdo e pedagogia que é próprio do mundo dos professores, sua forma particular de compreensão profissional. Tais experiências dariam sustentação ao que o mesmo autor denomina de sabedoria da prática dos professores, isto é, as máximas que guiam (ou fornecem racionalizações reflexas para) as práticas de professores talentosos.

Essa análise sobre inteligência ardilosa como um saber prático a ser mobilizado e transformado em saberes pedagógicos aptos ao exercício da docência na EP é revista pelo professor Saulo quando ele situa a aprendizagem para a docência como uma experiência vivida nas relações com outros professores mais experientes no interior da própria escola. Vejamos:

Eu acho que devia ser mais bem tratado ao entrar e que devia ter um curso específico dentro da área dele... Curso de que forma? Pegar um cara mais antigo, não é que ele não vai ensinar nada a ninguém, por exemplo, se você entrou aqui pra trabalhar de eletricista, por exemplo, e eu sou eletricista mais velho aqui não quer dizer que vá te ensinar não, eu vou te mostrar, vou te encaminhar de como é que tem sido feito antes, até então. Como é que tem sido dado o curso. Ora, você vai saber o que eu faço e vai poder introduzir as melhorias que você puder fazer, que você tiver condições de fazer. Essa é a maneira que eu penso. Mas isso às vezes não acontece. Contrata um cara e joga ele pra poder dar aula sem treinamento, sem nada, quer dizer... em tese o cara teria que ter o perfil do professor, será que tem? (Professor Saulo)

O professor Saulo aponta para o fato de que parte importante da aprendizagem para docência na EP dá-se na relação de trocas de experiências entre professores iniciantes e professores experientes. A experiência dos professores mais antigos da instituição apresenta-se como uma referência que baliza e orienta os primeiros passos na docência. Esse repertório de saberes advindos da experiência docente, impressa na figura do professor experiente, seria passível de ser acessado e intercambiado. A formação inicial e continuada para a docência ou, mais especificamente, a aprendizagem do saber-fazer na sala de aula parece ter pouca relação com as habilidades ou os conhecimentos aprendidos na academia ou em cursos de formação de professores. Como bem lembra Tardif (2007), as habilidades docentes têm forte caráter artesanal que se edifica também no acompanhamento de um novo professor (aprendiz) em relação a um mais experiente. A aprendizagem docente para os professores da EP iniciantes parece estar fortemente marcada por trocas 
de experiências entre professores, ou, quando não acontece na prática, tal recurso parece visto como uma estratégia de formação a ser desenvolvida.

Nessa mesma fala, o professor Saulo restringe essa aprendizagem para a docência ao treinamento voltado aos aspectos meramente práticos, do "como fazer". Tal visão, a nosso ver, parece ter íntima relação com uma visão de EP moldada segundo a cultura institucional da escola na qual trabalha. De maneira geral, nas escolas vinculadas ao Sistema S, o regime de contratação prioriza a escolha de profissionais que possuem mais experiência no mercado que a formação acadêmica. Soma-se a isso o fato de que os profissionais do ensino que atuam nessas instituições são nomeados pela própria ordem contratual não como professores, mas como instrutores. ${ }^{14}$

Nessa lógica, a responsabilidade docente ficaria reduzida à mera capacitação, não considerando a complexidade do ato educativo. Não convém aos interesses dominantes que o professor da EP, pela sua influência na formação do trabalhador, seja preparado criticamente para levantar questionamentos na relação ensino $x$ aprendizado sobre usos, objetivos e implicações da tecnologia e tampouco sobre a relação capital $x$ trabalho. Daí a opção de priorizar o ensino com a e da tecnologia, em detrimento de um processo que enfatize a tecnologia a serviço do ensino e o ensino sobre a tecnologia (Oliveira, 2000).

Essa visão dos sujeitos da pesquisa, de que o ensino na EP gravitaria em torno das questões que envolvem o ensino com a e da tecnologia, fica mais evidente quando lhes questionamos quais seriam, segundo a avaliação deles, as principais características do conhecimento profissional do professor do ensino técnico.

O cara domina o saber-fazer, a prática, tem um domínio prático muito bom, certo? E que também tem um domínio de classe, um domínio de público bom também. Isso pra mim, e que lógico, o saber-fazer técnico-teórico, execução, manual mesmo, e que tenha condição de dominar uma turma e que tenha condição de transmitir pra essa turma. O que vai determinar a capacidade e a condição do cara fazer, do cara ser, vai ser ele saber-fazer e saber transmitir. Então, se ele dominar esses dois negócios, aí não precisa dele ser um suprassumo dentro daquela linha que ele tem. Mas ele vai pelo menos conseguir começar a formar. Mas eu acho e eu penso assim: o cara tem que saber fazer da profissão, ser prático e tem que ter um domínio de público, tem que ter uma liderança, tem que ser líder. [...] ele tem que ter conhecimento de funcionamento industrial, de chão de fábrica, experiência, vivência de fábrica, real mesmo, o que acontece lá fora. (Professor Célio)

[...] olha, primeiro o conhecimento técnico, o saber-fazer, o saber técnico; segundo, o saber avaliar; e terceiro, o saber transmitir. (Professor Saulo)

14 Essa visão é manifesta, por exemplo, no decreto n. 2.208/1997, quando esse dispositivo legal permite que a figura do professor seja substituída pela do instrutor ou do monitor. 
Nesses discursos, os professores não deixam de pontuar que a docência na EP requer, além da experiência no mercado, um conjunto de habilidades pedagógicas que seriam próprias ao exercício dessa prática profissional. Saber avaliar o ato pedagógico, ter domínio de turma, saber transmitir e ter a capacidade de seduzir os alunos (capacidade de liderança) seriam habilidades que ajudariam a dar sentido, coerência e unidade ao fazer pedagógico na escola. À sua maneira e expressando marcas do contexto no qual sua cultura docente vai se edificando, os professores não deixam de reconhecer a necessidade e a importância de dominar um repertório de conhecimentos e habilidades pedagógicas.

Todavia, é importante ressaltar que, nos depoimentos dos professores, os conhecimentos do campo pedagógico necessários ao ensino na EP estão quase sempre diretamente ligados aos aspectos propriamente didáticos (Pimenta, 2003). A autora, ao tratar da abrangência dos conhecimentos da didática, afirma que essa área alcança três temáticas interdependentes: as finalidades do ensinar do ponto de vista político-ideológico (da relação conhecimento e poder, conhecimento e formação humana - direitos, igualdade, felicidade, cidadania), os temas psicopedagógicos (da relação conhecimento e desenvolvimento da capacidade de pensar e sentir, dos hábitos, das atitudes, dos valores) e as questões de ordem propriamente didáticas (organização dos sistemas de ensino, de formação, das escolas, da seleção de conteúdos de ensino, de currículos e organização dos percursos formativos, das aulas, dos modos e formas de ensinar, da avaliação, da construção de conhecimento).

Ao tomarmos essa compreensão como referência, podemos afirmar que o domínio dos conhecimentos do campo da didática, citado pelos professores pesquisados como necessários ao fazer pedagógico na EP, passa ao largo dos temas relacionados às finalidades do ensinar do ponto de vista político-ideológico. Essa interpretação nos remete à reflexão feita por Tanguy (1986) de que o ensino técnico, fundamentalmente transmissor de conhecimentos imediatamente úteis e práticos, é esvaziado de um saber social de caráter humano. Nesse contexto, as possibilidades de articulação entre a prática de ensino realizada na sala de aula e as relações de poder vigentes na sociedade brasileira ficam reduzidas a um saber-fazer que pouco contribuiu para a compreensão da EP para além do treinamento e da capacitação para o mercado.

Com esta análise, queremos direcionar nosso olhar para os objetos-condições de trabalho dessa categoria docente. É na prática cotidiana desses professores, em confronto com as condições de profissão, que os saberes da base da profissão são objetivados. A forte referência no mundo do trabalho, o peso da formação técnica, a crença difundida de que a EP seria o correlato do treinamento, a visão corrente de que esses professores não pertenceriam ao campo da educação, juntamente com a noção de que, para ser professor de disciplinas das áreas tecnológicas, mais vale o conhecimento dos conteúdos tecnológicos e a experiência no mercado do que propriamente a formação pedagógica, são alguns dos objetos-condições que constituem o contexto da prática docente na EP. Esses objetos-condições da profissão seriam geradores de certezas particulares sobre o agir docente, a mais importante das quais consistindo na confirmação, pelo docente, da própria capacidade de ensinar e de atingir bom desempenho nas atividades de ensino na escola. 
Daí a ênfase colocada pelos professores no domínio do conhecimento técnico, no saber prático (manual) ou no saber-fazer prático, na experiência acumulada na fábrica (inteligência ardilosa). O saber transmitir, avaliar e o domínio de turma e/ou a capacidade de liderança podem ser entendidos como habilidades decorrentes das anteriores e que seriam atualizadas, ressignificadas e aperfeiçoadas pela contextualidade da experiência docente na escola. Esses seriam os saberes da experiência na docência que fornecem aos professores certezas relativas a seu contexto de trabalho na escola, de modo a facilitar sua integração. Tais saberes não se encontram sistematizados em doutrinas ou teorias. São saberes práticos (e não da prática: eles não se superpõem à prática para melhor conhecê-la, mas se integram a ela e dela são partes constituintes enquanto prática docente) e formam um conjunto de representações com base nas quais os professores interpretam, compreendem e orientam sua profissão e sua prática cotidiana em todas as suas dimensões. Eles constituem a cultura docente em ação (Tardif, 2007).

Este entendimento dos depoentes, de que os saberes eminentemente práticos e técnicos têm centralidade no fazer pedagógico, contrasta com o conceito de educação tecnológica veiculado nos ordenamentos legais da EP no Brasil, como também na discussão teórica no campo dos estudos sobre trabalho e educação. $\mathrm{O}$ conceito de educação tecnológica, “[...] associado a uma concepção ampla e universal de formação, buscando o desenvolvimento integral do trabalhador, priorizando a formação de uma consciência crítica, o domínio de princípios científicos e tecnológicos, o desenvolvimento das habilidades socioafetivas, cognitivas e éticas"(Burnier, 2007, p. 353), parece ter ainda muita dificuldade de ocupar o universo de reflexões e ações pedagógicas dos professores dessa modalidade de ensino.

Essa constatação é de certa forma ratificada quando questionamos os professores sobre o conceito que eles tinham da formação continuada para a docência na EP. Eis alguns depoimentos:

Isso tem que ter mesmo, inclusive eu pessoalmente estou fazendo uma capacitação agora pra um equipamento novo que eu ainda não trabalhei nele, trabalhei no mais antigo, agora vou dar uma aula do mais novo. Eu pedi uma capacitação a um colega meu, uma capacitação de 16 horas/aula pra poder ter condições de dar aula. Tem que ser constante, porque todo dia na indústria tem coisa nova, o que tinha dez anos atrás já tá obsoleto quase, muda tudo. Tem que ter sim [...] Aqui mesmo, na escola $\mathrm{A}$ tem os próprios colegas que têm vivência naquela área que a gente não tem ainda. $\mathrm{E}$ atualmente tem muitos colegas fazendo mestrado e doutorado. A instituição tem propiciado para os professores. (Professor Célio)

Você tem que estar sempre aperfeiçoando, a tecnologia está sempre mudando. Terminou um negócio, certo, enfileira ele com outro senão você estagna. [...] Na própria instituição tem, tem interna e tem externa. Se você ficar sabendo e ver algum curso que queira fazer fora, você comunica a entidade e se ela achar por bem que você deve fazer você vai fazer, assim como ela às vezes te matricula ou pergunta se você quer ser matriculado em alguns cursos, e, fora 
isso, vamos dizer assim, de seis em seis meses, de ano em ano, tem dentro da própria entidade, por exemplo, a entidade tem lá, cinco mil, seis mil instrutores, então monta cursos, monta cursos de férias, faz a propaganda e te convida pra participar disso aí. Fora isso aí você vai em seminário, em feiras, em congressos [...]. (Professor Saulo)

Nesses relatos, os professores associam a formação continuada para a docência à atualização dos conhecimentos tecnológicos, seja em curso de curta duração fora e dentro da instituição, seja em cursos de pós-graduação na área específica (tecnológica), seja na participação de eventos, como congressos e seminários vinculados, à área tecnológica de seu interesse. O domínio do conhecimento tecnológico apresenta-se, portanto, como fulcral ao exercício da prática docente na EP.

É interessante observar que, em nenhum momento, o tema da formação continuada esteve associado à formação pedagógica. Esse tipo de formação, apesar de ser um ponto lacunar na formação desses professores, constitui elemento pouco potente ou relevante para o processo de constituição de sua identidade docente. Como afirma Dubar (1997), o espaço de reconhecimento das identidades é inseparável do espaço de legitimação dos saberes e das competências associadas às identidades. A transação objetiva entre os indivíduos e as instituições é antes de tudo aquela que se organiza à volta do reconhecimento e do não reconhecimento das competências, dos saberes e das imagens de si, que constituem os núcleos duros das identidades reivindicadas.

$\mathrm{Na}$ visão dos professores investigados, sua cultura docente seria fortemente marcada pelo que Tardif (2007) denomina de "saberes mestres". O domínio do conhecimento tecnológico em mutação forneceria aos docentes um repertório de conhecimentos e habilidades suficientes ao pleno exercício da docência na EP. É como se esse conhecimento a ser transmitido possuísse, em si mesmo, valor formador, capaz de garantir a atividade de transmissão na sala de aula. Em contraposição a essa perspectiva, Tardif alerta para o fato de que nenhum saber é por si mesmo formador. Os professores não possuem mais saberes-mestres, cuja posse venha garantir sua maestria: saber alguma coisa não é mais suficiente, é preciso também saber ensinar.

\section{CONSIDERAÇÕES FINAIS}

Ao finalizarmos este trabalho, tentaremos, nesta última parte do texto, revisitar os achados mais significativos da pesquisa, no intuito de apontar, de forma sintética, as contribuições deste estudo ao avanço do processo de significação dos conteúdos e das características dos saberes da base profissional dos docentes da EP.

A primeira questão que saltou aos nossos olhos no decorrer da pesquisa foi como os dois professores referem-se à experiência na fábrica ou no mercado como fonte de conhecimentos fundamentais ao exercício da docência na EP. Alguns elementos da pedagogia da fábrica seriam anexados ou transmutados à cultura docente em ação. Nesse tempo e espaço de vivências profissionais, dar-se-ia, segundo os professores, a formação inicial e básica para o exercício da docência na EP. São aprendizagens de ordem técnica, relacionais, corporais e intelectuais que, de certa forma, são organizadas 
e atualizadas pelos professores com vistas ao atendimento dos diversos interesses e necessidades dos aprendizes, da instituição e dos próprios docentes.

Outra fonte de conhecimentos e habilidades mobilizada pelos nossos sujeitos de pesquisa diz respeito às trocas de experiências efetuadas entre professores iniciantes e experientes. Parte da formação inicial e/ou continuada para a docência dá-se de maneira informal, nos interstícios do cotidiano na escola. Esses intercâmbios nascem do desejo individual dos professores de buscar soluções para as dificuldades de aprendizagem dos alunos, para a organização das aulas e seleção dos conteúdos das disciplinas. Fica evidenciado na pesquisa um sério quadro de voluntarismo e isolamento dos professores quando eles pleiteiam seu direito à formação continuada no cotidiano da escola.

Soma-se às duas fontes de saberes anteriores uma terceira que constituiria parte significativa do repertório de saberes que estão na base da profissão docente na EP. Segundo os sujeitos da pesquisa, o domínio do conhecimento tecnológico (conteúdo específico) ocuparia posição central nesse repertório. O conhecimento, a atualização e o acompanhamento das mutações dos conhecimentos tecnológicos seriam suficientes para garantir o domínio do conteúdo teórico-prático necessário ao exercício da docência na sala de aula e, sobretudo, à validação por parte dos alunos da competência profissional e do "eu profissional" do professor.

A pesquisa também mostrou que os conhecimentos pedagógicos, mesmo sendo citados como necessários à prática docente na sala de aula, aparecem, segundo a percepção dos professores, numa posição de baixo status nas hierarquias dos saberes necessários ao ensino na EP. Quando citados pelos professores, os conhecimentos pedagógicos aparecem fortemente marcados pela lógica de uma competência técnica (saber-fazer) desvinculada de uma competência política. Tal fato pode ser explicado pelas fortes limitações impostas pela falta de acesso (dentro e fora da escola) a um debate mais qualificado sobre a função social da escola e da educação profissional, informado pelo argumento de cunho crítico que busca estabelecer relações entre educação tecnológica, ensino técnico e formação humana. Todavia, nossos depoentes reafirmam a importância do saber pedagógico e apresentam informações que sugerem que eles se sentem carentes de conhecimentos e competência para agir em situação de ensino e esperam ter mais oportunidades de se desenvolverem nesse campo de saber.

Sustentados pelos dados deste trabalho, podemos dizer que ensinar na EP e na educação regular não é fazer a mesma coisa, ou melhor, não é objeto de igual consideração. As pesquisas sobre os saberes docentes precisam desfazer certa noção de equidade no campo da profissionalidade docente. Esse campo de intervenção profissional comporta uma dimensão social fundamental e se insere em relações sociais marcadas pela negociação com um tipo de trabalho específico, com seus conteúdos, com suas exigências próprias, com suas finalidades situadas e com suas estratégias de controle e autonomia (Lessard; Tardif, 2003).

Não há uma cultura docente comum ao conjunto dos professores, mas culturas profissionais produzidas por eles no processo de interação cotidiana com seu trabalho, processo este estruturado por diversas condições e contratos sistemáticos - ordens escolares, setores de ensino, campos de ensino, estabelecimentos de 
ensino e ambientes socioeconômicos da região -, nos quais exercem sua profissão. Há, portanto, que se fazer revelar a cultura docente dos profissionais dos diversos campos disciplinares, daqueles que militam com disciplinas profissionalizantes, dos que trabalham com os portadores de necessidades especiais, dos que atuam na universidade, dos educadores de jovens e adultos, entre outros profissionais que compõem o vasto espectro da educação escolar. Todos nós somos professores, pertencemos ao professorado, produzimos e partilhamos saberes e práticas comuns, mas há hierarquias, há níveis e graus e imagens bastante diferenciadas, diversidade de práticas, de salário, de carreira, de titulação e de prestígio. Os professores são vistos com traços diferenciados e veem o magistério com características bem distintas (Arroyo, 2000).

Nosso objetivo com este estudo foi mostrar que o ofício docente na EP é feito de saberes que trazem as marcas do caráter situado do trabalho desses professores. Ao confirmar essa hipótese, demos uma pequena contribuição ao avanço do processo de profissionalização desses professores, apresentando algumas das características dos saberes próprios do ensino dos professores da EP. Num momento em que se fazem urgentes a discussão e a definição de uma política de formação inicial e continuada de professores para a educação profissional, inexistentes no país, acreditamos que os impasses e as potencialidades vividos por esses docentes - e aqui apontados possam constituir-se em pistas para a construção de tais políticas.

\section{REFERÊNCIAS}

André, Marli. A pesquisa sobre formação de professores no Brasil - 1990-1998. In: Candau, Vera Maria (Org.). Ensinar e aprender: sujeitos, saberes e pesquisa. Rio de Janeiro: DP\&A, 2000. p. 83-100.

Simões, Regina Helena; Carvalho, Janete Magalhães; Brzezinski, Iria.

Estado da arte da formação de professores no Brasil. Educação E̛ Sociedade, Campinas: CEDES, v. 20, n. 68, p. 301-309, dez. 1999.

Arroyo, Miguel Gonzales. Ofício de mestre: imagens e autoimagens. Petrópolis: Vozes, 2000.

Brasil. Decreto 7.566, de 23 de setembro de 1909. Diário Oficial da União, Poder Executivo, Brasília, DF, 26 set. 1909. Seção 1, p. 6.975.

Lei n. 4.024, de 20 de dezembro de 1961. Fixa as Diretrizes e Bases da Educação Nacional. Diário Oficial da União, Poder Executivo, Brasília, DF, 27 dez. 1961.

. Resolução n. 2, de 26 de junho de 1997. Dispõe sobre os programas especiais de formação pedagógica de docentes para as disciplinas do currículo do ensino fundamental, do ensino médio e da educação profissional em nível médio. Resoluções. Brasília: Ministério da Educação, 1997. Disponível em: <http://portal.mec.gov.br/>. Acesso em: 20 out. 2014.

Ministério da Educação. INEP. Censo da Educação Profissional 1999. Escolar 2001. Brasília, 1999. Disponível em: <http://portal.inep.gov.br/educacao-profissional〉. Acesso em: 1 set. 2014. 
.Ministério da Educação (MEC). Rede Federal de Educação Tecnológica. Disponível em: $<$ http://portal.mec.gov.br/setec/index.php?option=content\&task=view\&id= Intemid=207>. Acesso em: 9 jun. 2008.

Brzezinski, Iria (Org.). Formação de profissionais da educação (1997-2002). Brasília: Ministério da Educação, INEP, 2006. p. 1-52.

Burnier, Suzana; Cruz, Regina Mara Ribeiro; Durães, Marina Nunes; Paz, Mônica Lana; Silva, Adriana Netto; Silva, Ivone Maria Mendes. Histórias de vida de professores: o caso da educação profissional. Revista Brasileira de Educação, Rio de Janeiro: ANPEd; Campinas: Autores Associados, v. 12, n. 35, p. 343-358, 2007. Disponível em: <http://www.scielo.br/pdf/rbedu/v12n35/a13v1235.pdf >. Acesso em: 15 ago. 2011.

Coleman, James S.; Hoffer, Thomas. Equality of educational opportunity. Washington: U.S. Government Printing Office, 1966.

DEjours, Christophe. Inteligência operária e organização do trabalho: a propósito do modelo japonês de produção. In: Hirata, Helena (Org.). Sobre o modelo japonês. Tradução de Rosaura Eichenger, Maria de Lourdes Vignoli e Hedy Helena de Menezes Pereira. São Paulo: Edusp, 1993.

Dubar, Claude. A socialização: construção das identidades sociais e profissionais. Tradução de Andréa Stahel M. da Silva. Porto: Porto Editora, 1997.

Gauthier, Clemont; Martineau, Stephane; Desbiens, Jean-Fraçois. Por uma teoria da pedagogia. Tradução de Francisco Pereira. Ijuí: Editora Unijuí, 1998.

Kaufmann, Jean C. L'Entretien comprehensive. Paris: Éditions Nathan, 1996.

Kuenzer, Acácia Zeneida. Educação profissional: novas categorias para uma pedagogia do trabalho. Boletim Técnico do Senac, Rio de Janeiro: SENAC, v. 25, n. 2, p. 19-29, 1999.

Lessard, Claude; TARdif, Maurice. Les identités enseignantes: analyse de facteurs de différenciation du corps enseignant québécois 1960-1990. Roy, Gérard-Raymond (Super.). Editions du CRP, Sherbrooke, Université de Sherbrooke, Quebec, 2003.

Macieira, Daniel de Souza. Limites e possibilidades da formação inicial de professores da educação profissional através do Programa Especial de Formação Pedagógica de Docentes, segundo as representações de seus egressos. 2009. 209f. Dissertação (Mestrado em Educação Tecnológica) - Centro Federal de Educação Tecnológica de Minas Gerais, Belo Horizonte, 2009.

Martin, Daniel. Nature du savoir enseignant: analyse des écrits anglo-saxons. Cabiers de la Recherche en Éducation, Quebec: Sherbrooke, v. 1, n. 2, p. 253-286, 1993.

Oliveira, Maria Rita Neto Sales. Formação e profissionalização dos professores do ensino técnico. In: Aranha, Antônia Vitória; Cunha, Daisy Moreira; Laudares, João Bosco (Orgs.). Diálogos sobre o trabalho: perspectivas multidisciplinares. Campinas: Papirus, 2005. p. 15-37.

Peterossi, Helena Gemignani. Formação do professor para o ensino técnico. São Paulo: Edições Loyola, 1994. 
Pimenta, Selma Garrido. Didática, didáticas específicas e formação de professores: construindo saberes. In: Tiballi, Elianda Figueiredo Arantes; Chaves, Sandramara Matias (Orgs.). Concep̧̧óes e práticas em formação de professores: diferentes olhares. Rio de Janeiro: D\&P, 2003. p. 49-56.

Schon, Donald. Formar professores como profissionais reflexivos. In: NóvoA, António (Org.). Os professores e sua formação. Lisboa: Dom Quixote, 1992. p. 79-91.

Shulman, Lee S. Those who understand: knowledge growth in teaching. Educacional Researcher, Washington: AERA, v. 15, n. 2, p. 4-14, fev. 1986.

Tanguy, Lucie. Los conocimientos transmitidos a los futuros obreros. Tempora, La Laguna (Espanha): Servicio de Publicaciones de la Universidad de La Laguna, n. 7, p. 11-28, jan./jun. 1986.

TARDif, Maurice. Saberes docentes e formação profissional. Tradução de Francisco Pereira. 8. ed. Petrópolis: Vozes, 2007.

. Lessard, Claude. Le travail enseignant au quotidien. Experience, infractions humaines et dilemes professionnels. Paris: DeBoeck, 1999.

. O trabalho docente: elementos para uma teoria da docência como profissão de interações humanas. Tradução de João Batista Kreuch. 4. ed. Petrópolis: Vozes, 2008.

Lahaye, Louise. Os professores face ao saber: esboço de uma problemática do saber docente. Teoria E Educação, Porto Alegre: Pannonica, n. 4, 1991. Woods, Peter. Aspectos sociais da criatividade do professor. In: NóvoA, António (Org.). Profissão professor. Tradução de Irene Lima Mendes, Regina Correia, Luísa Santos Gil. Porto: Porto Editora, 1995.

\section{SOBRE OS AUTORES}

Geraldo Silvestre Silva Júnior é mestre em educação tecnológica pelo Centro Federal de Educação Tecnológica de Minas Gerais (CEFET-MG). E-mail: geraldosilvestre@yahoo.com.br

José Ângelo Gariglio é doutor em educação pela Pontifícia Universidade Católica do Rio de Janeiro (PUC-Rio). Professor da Universidade Federal de Minas Gerais (UFMG).

E-mail: angelogariglio@hotmail.com

Recebido em junho de 2012 Aprovado em novembro de 2013 